Proc. Indian Acad. Sci., Vol. 88 A, Part I, Number 4, August 1979, pp. 263-278, o printed in India.

\title{
Kinetic studies on the interaction of gold(III) with nucleic acids. I. Native DNA-Au(III) system-spectrophotometric studies
}

\author{
CHHABINATH MANDAL and U S NANDI \\ Department of Inorganic and Physical Chemistry, Indian Institute of Science, \\ Bangalore 560012
}

MS received 27 March 1979

\begin{abstract}
Kinetics of the interaction of $\mathrm{Au}$ (III) with native calf thymus DNA has been studied spectrophotometrically to determine the kinetic parameters and to examine their dependency on the concentrations of DNA and Au(III), temperature, ionic strength and pH. The reaction is of the first order with respect to both the nucleotide unit of DNA and Au(III) in the stoichiometry of $2: 1$ respectively. The rate constants vary with the initial ratio of DNA to Au(III) and is attributed to the effect of free chloride ions and the existence of a number of reaction sites with slight difference in the rate constants. The activation energies of this interaction have been found to be $14-16 \mathrm{kcal} / \mathrm{mol}$. From the effect of ionic strength the reaction is found to occur between a positive and a negative ion in the ratelimiting step. The logarithm of rate constants are the linear function of $\mathrm{pH}$ and the slopes are dependent on the $r$-values. A plausible mechanism has been proposed which involves a primary dissociation of the major existing species $\left(\mathrm{AuCl}_{2}(\mathrm{OH})_{2}\right)^{-}$, to give $\left(\mathrm{AuCl}_{2}\right)^{+}$whi th then reacts with a site in the nucleotide unit of DNA in the rate-limiting step followed by a rapid binding to another site on the complementary strand of the DNA double helix. There exist a number of binding sites with slight difference in reactivity.
\end{abstract}

Keywords. Kinetics; Au(III); DNA; spectrophotometry; nucleic acids; oquilibrium studies; pH effect.

\section{Introduction}

Gold(III) is well known to interact with the nucleic acids and their constituents (Pillai 1974; Pillai and Nandi 1973; Gibson 1969; Gibson et al 1971). Pillai (1974) and Pillai and Nandi (1973) characterised the binding of Au(III) with native and denatured DNAs and RNA. According to them these types of DNA-Au (III) complexes are formed with a red shift in the ultraviolet spectra accompanied by drastic fall in viscosity. They observed that three types of complexes are formed with the DNA(P) to $A$ (III) ratios $2: 1,1: 1$ and $1: 1 \cdot 8$. Binding to both the phosphate and base moieties was predicted, the most probable sites in the bases being $\mathrm{N}-1 / \mathrm{N}-7$ of adenine, $\mathrm{N}-3$ of thymine, $\mathrm{N}-7$ and/or $\mathrm{C}_{.} \mathrm{O}$ of guanine and N-3 of cytosine. They suggested that $\mathrm{Au}(\mathrm{III})$ might cross-link the complementary strands of DNA. Au(III) was found to be partially selective towards 
the AT base pairs. Gibson (1969) and Gibson et al (1971) studied the reaction of Au(III) with the nucleotides, polynucleotides, yeast RNA and denatured DNA. They also observed partial selectivity with regard to both the stoichiometry and rate, the specificity of $A u$ (III) toward deoxyribonucleotides being in the order d $A M P>d$ GMP $>$ d CMP $>$ d TMP.

The reaction of $\mathrm{Au}$ (III) with DNA is quite slow and is suitable for kinetic siudies using the conventional techniques for slow reactions. In the present paper we describe the kinetics of the interaction of $\mathrm{Au}$ (III) with native calf thymus DNA under various conditions of concentrations of DNA and Au(III), temperature, jonic strength and $\mathrm{pH}$ of the reaction mixture.

\section{Materials and sample preparation}

Highly polymerised calf thymus DNA was purchased from Schuchardt and Company, Munich (prepared by the method of Zamanhof (1958) and was used without further purification. The dissolution of DNA was done by adding small amounts of acetate buffer to solid DNA at intervals of 4-6 hr for about 4 days maintaining at $0-4^{\circ} \mathrm{C}$ and by occasional gentle shaking. The acetate buffer contained sodium acetate $(0.01 \mathrm{M})$, sodium perchlorate $(0.01 \mathrm{M})$ and adequate quantity of acetic acid to adjust the desired pH. The stock DNA solution containing about $1 \mathrm{mg} / \mathrm{ml}$ was standardised using $\epsilon(P)_{\max }$ as $6.7 \times 10^{-3}$ OD $\mathrm{M}^{-1}$ $\mathrm{cm}^{-1}$ and diluting an aliquot by adding the buffer to get all absorbance at $258 \mathrm{~nm}$ in the range $0 \cdot 6-0.8 \mathrm{OD}$ in a cell of path length one $\mathrm{cm}$.

Chloro-auric acid, $\mathrm{HAuCl}_{4} \cdot 3 \mathrm{H}_{2} \mathrm{O}$, was supplied by Johnson Mathey Chemicals Limited, London. The stock solution was prepared in doubly distilled water. The concentration of the stock Au(III) solution was determined spectrophotometrically according to Vydra and Celikovsky (1958) using $\epsilon_{\text {mexisis) }}=5.5 \times 10^{2}$ $O D \mathrm{M}^{-1} \mathrm{~cm}^{-1}$ as well as by iodine-thiosulfate method of Gooch and Morley (1899). The results obtained by the two methods agreed within the experimental accuracy.

All the other reagents e.g., sodium perchlorate, sodium acetate, sodium chloride, acetic acid, etc., were of analytical reagent grade. All solutions were prepared in doubly distilled water ( $\mathrm{pH}=6.6$ to 6.8$)$.

\section{Experimental}

The UV spectra were taken using an UNICAM SP 700A double beam automatic recording spectrophotometer equipped with heating and thermostating devices. Two matched quartz cells of path length $1 \mathrm{~cm}$ were used for taking sample and reference solutions. Since Au(III) absorbs in the UV region difference spectra of the DNA-Au(III) solutions were taken against Au(III) solution containing equal initial concentrations of $\mathrm{Au}$ (III) in both the solutions. The desired volumes of stock Au(III) solutions were added to the buffer medium $48 \mathrm{hr}$ earlier before starting the reaction so as to attend the hydrolytic equilibria of $\mathrm{Au}$ (III).

For kinetic experiments, the transmittances at two different wavelengths, e.g., 250 and $280 \mathrm{~nm}$ were recorded at desired intervals of time. Time taken to record the transmittance at a given wavelength was about 2 sec. Experjments were carried 
out in an airconditioned room maintained at $25^{\circ}-26^{\circ} \mathrm{C}$. For experiments above room temperature an accessory (SP 770 and SP 775, constant temperature cell unit and electrical controller) of the spectrophotometer was used. The temperature could be controlled to within $\pm 0.05^{\circ} \mathrm{C}$.

In the kinetic studies of nucleic acid-metal ion systems using spcctrophotometer, different parameters, e.g., absorbances at $260 \mathrm{~nm}$ (Liebe and Stuchr 1972a, b) and $290 \mathrm{~nm}$ (Williams 1968) and the absorbance ratio A250/A270 (Horacek and Drabuik 1971) have been used to follow the course of the reactions. For our system we have used the ratio, $A 250 / A 280$, because this parameter varies linearly with the extent of reaction but not of $A 250, A 260$, A280, etc. (figure 1).

\section{Treatment of kinetic data}

The kinetic data were treated in two different ways, reaction kinetics and denaturation kinetics.

\subsection{Reaction kinetics}

In this method the process was considered to be a reaction between the ligand sites of DNA and Au(III). Using a FORTRAN IV computer program the experimental data were subjected to fit the classical rate equations for a number of combinations of stoichiometries $(2: 1,1: 1$ and $1: 2)$ and orders (first and second orders with respect to each) of the nucleotide unit of DNA and Au(III).

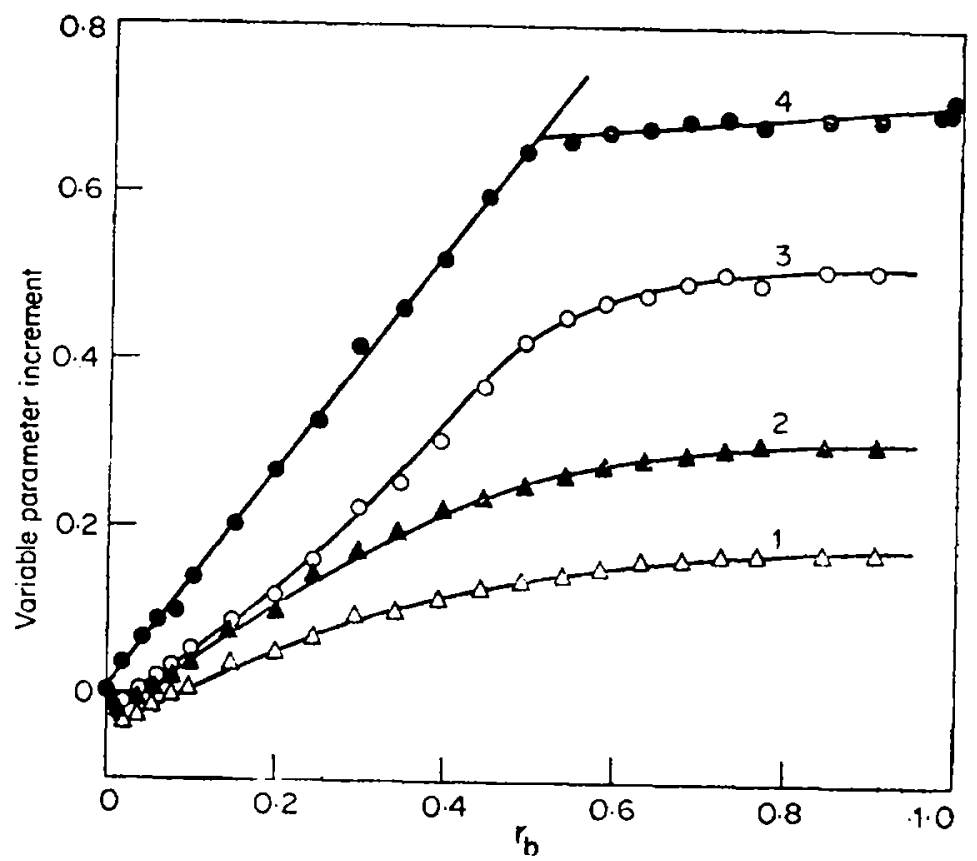

Figure 1. Plot of variable parameter increment vs $r_{3}$ value. Curvo 1, for $\triangle A 250$; Curve 2, for $\triangle A 260$; Curve 3 , for $\triangle A 280$ and Curve 4 , for $-\triangle(A 250 / A 280)$. Condition : DNA-Conc $=1.06 \times 10^{-1} \mathrm{M}(\mathrm{P}) ; \mathrm{pH}=5.0 ;$ Temperature $=30.0^{\circ} \mathrm{C}$; Buffer : Na-acotate $(0.01 \mathrm{M})+\mathrm{NaClO},(0.01 \mathrm{M})+$ acetic acid. 
For all these combinations, the functions $\left(f_{R}(x)\right)$ of the extent of reaction $(x)$ were derived and the standard deviations of the plots of $f_{R}(x)$ vs time were calculated. The minimum standard deviation of this plot from a straight line indjcated the best fit of the experimental data for a particular combination. From the slope of the best fitted plot the rate constants could be calculated. The rate constants derived by this method were termed as reaction rate constants $\left(k_{R}\right)$.

\subsection{Denaturation kinetics}

In this method, the process has been viewed as an one-dimensional transformation of DNA from its ordered native state to a disordered denatured state as revealed by the drastic change in optical and hydrodynamic properties of the DNA molecule. This leads to the following differential kinetic equation

$$
d x / d t=k_{\mathrm{D}}\left(a_{0}-x\right)^{*} .
$$

The solutions of (1) are

$$
\frac{1}{n-1}\left\{\frac{1}{\left(a_{0}-x\right) n-1}-\frac{1}{a_{0} n-1}\right\}=k_{D} \cdot t(\text { for } n \neq 1)
$$

and $\ln a_{0}\left(\left(a_{0}-x\right)\right)=k_{D} \cdot t$

(for $n=1$ )

where $a_{0}=$ total denaturation; $x=$ extent of denaturation at a time $t$ and $n=$ overall order of denaturation.

The left hand sides of (2a) and (2b) are the functions of $x$ and $n$; let these be denoted by $f_{D}(x, n)$. If this function is plotted against $t$ with the proper value of $n$ a straight line will be obtained.

The observation that no unique integer value of $n$ satisfied all the experimental results led us to develop a computer program which determines the value of $n$ by iterative method upto the first place of decimal. The method is based on the principie of calculating $J_{D}(x, n)$ with the values of $n$ between 0.0 to 4.0 at an interval of 0.1 and determining the standard deviation of a straight line plot of $f_{D}(x, n)$ vs $t$ corresponding to each $n$ value by least square method. While calculating the standard deviation the program goes on selecting the smaller and smaller values finally detecting the $n$ value which gives the minimum standard deviation (this corresponds to the best fit). With this final value of $n$ it calculates the slope of the best fitted straight line and also plots a graph of $J_{D}(x, n)$ vs $t$ which is obviously a straight line. The validity of this method has been tested for two hypothetical reactions of order 2.0 and 2.5 ; the orders calculated using this program are exactly 2.0 and 2.5 respectively. The rate constants derived by this methed are referred to as denaturation rate constants $\left(k_{D}\right)$.

The extent of denaturation is abtained from the following relation

$$
x=\frac{P_{0}-P_{i}}{P_{0}-P_{a}},
$$

where $P_{0}, P_{t}$ and $P_{a}$ are the values of the parameter at the beginning, at a time and at the completion of the reaction.

All the calculations were done using an IBM 360/44 digital computer. 


\section{Equillbrim resalts}

A series of equilibrium experiments were carried out with $r$-values ranging from 0.0 to 2.0 at $\mathrm{pH}=5.0(r=\mathrm{mol}$ of $\mathrm{Au}(\mathrm{III}) / \mathrm{niol}$ of DNA (P)). For this set of $r$-yalues, a set of $r_{3}$-values were calculated assuming the value of an apparent association constant $(\mathrm{Kac})$ to be $10^{8} \mathrm{M}\left(r_{b}=\mathrm{mol}\right.$ of $\mathrm{Au}(\mathrm{III})$ bound to DNA/mol of DNA (P)). Pillai (1974) determined $r_{5}$-values corresponding to a set of $r$ values for a set of experiments at $\mathrm{pH}=5 \cdot 6$. A calculation of $\mathrm{Kac}$ using these values of $r$ and $r_{3}$ gave the value of $\mathrm{Kac}=10^{5} \mathrm{M}$. But as the Au(III) binds more strongly at lower $\mathrm{pH}$, we assume the value of $\mathrm{Kac}=10^{8} \mathrm{M}$ at $\mathrm{pH}=5 \cdot 0$. In fact, calculation of $r_{b}$-values using $\mathrm{Kac}$ more than $10^{5} \mathrm{M}$ does not affect our results.

The reaction mixture was allowed to attain the equilibria and spectra were recorded in the UV region $(200-330 \mathrm{~nm})$. From these spectra the absorbance at $250,260,270$ and $280 \mathrm{~nm}$ was determined along with the ratio of the absorbance at 250 to that at $280 \mathrm{~nm}(A 250 / A 280)$. The absorbance maximum originally at $258 \mathrm{~nm}$ with pure DNA solution $(r=0.0)$ shifted to a maximum value of 268 $\mathrm{nm}$ when $r=2 \cdot 0$.

Figure 1 presents the plats of $\triangle A 250, \triangle A 260, \triangle A 280$ and $-\triangle(A 250 / A 280)$ against $r_{b}$-values. The prefix $\triangle$ indicates the increment in absorbances $(A)$ at the wavelengths shown by suffices taking the value of absorbance of the native DNA as origin. The absorbances at the above mentioned wavelengths show an initial decrease at very lcw values of $r(\leqslant 0.06)$ and then a continuous increase upto $r=1 \cdot 2$, beyond which again there is a decreasing trend.

The ratio $A 250 / A 280$ decreases regularly with increasing $r_{h}$ (or $r$ ) values. It can be seen from figure 1 that the plat of negative increment, $-\triangle(A 250 / A 280)$, against $r_{b}$ is a straight line which shows a sharp break near $r_{b}=0.5$. It is worthy to note that this parameter shows a steep rise upto $r_{b}=0.5$ and then increases very slawly. Hence this is a characteristic for a complex formation up to $r=0.5$, beyond which the change in this parameter is very small and constitutes only $5 \%$ of the total change.

\section{Kinetic resolts}

A series of experiments were carried out with different experimental conditions and the data were analysed by the methods of reaction and denaturation kinetics. In the reaction kinetics methed of treatment, the rate equations corresponding to first order with respect to both the nucleotide unit of DNA and $A u(I I I)$ in the respective stoichiometry of $2: 1$ gave the best fit for all the experiments. Only $60-70 \%$ of the reaction fitted to a straight line and then deviate giving lower slope.

In the denaturation kinetics method of treatment, the overall order $(n)$ of denaturation varies with the $r$-values of the reaction mixture. The denaturation order is determined only by the $r$-value and is independent of any other condition. With $r=0.5$ the value of $n$ is $2.0 \pm 0.1$, which is obvious for a reaction obeying the above mentioned rate equation in reaction kinetics. (In this method of order determination a deviation of \pm 0.1 is observed even for reactions with identical conditions.) With $r$-values higher than 0.5 the order becomes less-from a number of experiments a generalised statement can be made that the orders are $1.8 \pm 0.1$ for $r=1.0$ and $1.6 \pm 0.1$ for $r=1.5$. For the intermediate values 
of $r$ the orders fall in between. In table 1 the results of a typical set of experiments are piesented.

\section{Effect of DNA-and Au(II)-concentrations}

The effect of concentrations was studied in four different ways:-

(i) by varying $r$-values (or $\mathrm{Au}$ (III)-concentrations) at a fixed DNA concentration,

(ii) by varying $r$-values (or DNA-concentrations) at a fixed $\mathrm{Au}$ (III) concen. tration,

(iii) by varying $r$-values (or $\mathrm{Au}$ (III)-conrentrations) at a fixed DNA- and free Cl- ion-concentrations (will be clarified later), and

(iv) by varying both the DNA- and Au(III)-concentrations at fixed r-values.

Figure 2 presents the plots of reaction rate constants against $r$-values for the experimental sets with variable $r$-values (case 1,2 and 3 ) at $\mathrm{pH}=5 \cdot 0$. It can be seen that the reaction rate constants always increase with the decrease in $r$-value. A comparison of the curves 1 and 2 in figure 2 reveals that this increase is more in the case when the concentration of Au(III) is varied (curve 1) than in the case of varying DNA concentration (curve 2). This trend of variation is also observed in ancther set of experiments at $\mathrm{pH}=4 \cdot 0$. When both the DNA and Au(III) concentrations are increased at constant $r$-values (case 4 ) the reaction rate constants are found to decrease. Strictly speaking the reaction rate constant should not vary with the $r$-value of the concentration of the reactants but this type of dependence of rate constants on the DNA-and metal ion-concentrations was observed by tarlier workers working on the Cu-DNA (Liebe and Stuchr 1972a) and Hg-DNA (Williams 1968) systems.

The strong dependence of reaction rate constants on the r-value in the case of varying $\mathrm{Au}$ (III)-concentration (case 1 ) is considered to be due to the effect of free $\mathrm{Cl}^{-}$ions. Like Pt(II)-DNA system (Horacek and Drobnik 1971) the Au(III)DNA system is also very sensitive to $\mathrm{Cl}^{-}$ions; the reaction at $\mathrm{pH}=5.0$ is almost inhibited when $0.2 \mathrm{M} \mathrm{NaCl}$ is plesent in the reaction medium. In this system the major species of $\mathrm{Au}(\mathrm{III})$ is $\left(\mathrm{AuCl}_{2}(\mathrm{OH})_{2}\right)^{-}$after the hydrolytic

Table 1. Reaction and denaturation rate constants with different $r$ values at constant DNA concentration $\left(=1.642 \times 10^{-4} \mathrm{M}(\mathrm{P}) ; \mathrm{pH}=5.0\right.$ and at room temperature)

\begin{tabular}{|c|c|c|c|}
\hline r-value & $\begin{array}{c}\text { Reaction rate } \\
\text { constant }\left(k_{R}\right) \\
\text { (in lit-mol-1 } \text { min }^{-1} \text { ) } \\
\times 10^{-2}\end{array}$ & $\begin{array}{l}\text { Denaturation } \\
\text { rate constant } \\
\left(k_{D}\right) \times 10^{2} \\
\left(\text { in } \text { min }^{-1}\right)\end{array}$ & $\begin{array}{c}\text { Denaturation } \\
\text { order }\end{array}$ \\
\hline 0.50 & $0 \cdot 9121$ & 0.3302 & $2 \cdot 1$ \\
\hline 0.75 & 0.6431 & 0.7358 & $1 \cdot 9$ \\
\hline $1 \cdot 00$ & 0.5016 & 1.007 & $1 \cdot 9$ \\
\hline $1 \cdot 25$ & 0.4105 & $1 \cdot 172$ & $1 \cdot 6$ \\
\hline $1 \cdot 50$ & $0 \cdot 3567$ & $1 \cdot 273$ & $1 \cdot 6$ \\
\hline
\end{tabular}




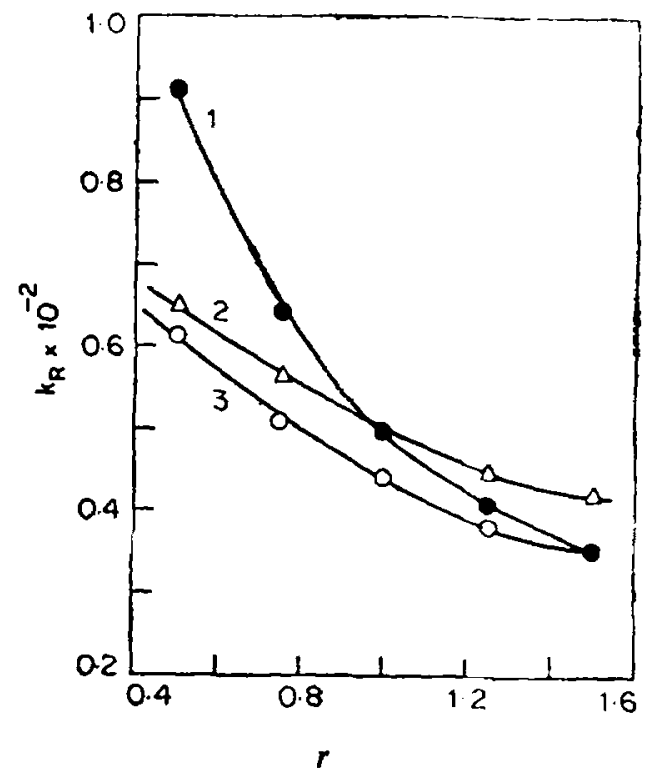

Figure 2. Plot of reaction rate constants $\left(k_{R}\right)$ vs $r$-value for Curve 1 , with fixed DNA-Conc $\left(=1.642 \times 10^{-4} \mathrm{M}(\mathrm{P})\right)$, Curve 2, with fixed $\mathrm{Au}(\mathrm{III})$-Conc $(=1.642$ $10^{-4} \mathrm{M}$ ) and Curve 3, with fixed DNA-and free $\mathrm{Cl}^{-}$ion-concentrations. Condition : $\mathrm{pH}=5 \cdot 0$ room temperature; Buffer : same as in figure 1 .

equilibrium is attended (Gibson 1969). The formation of this species from $\mathrm{AuCl}_{4}-$ adds two equivalents of free $\mathrm{Cl}^{-}$ions to the reaction medium. Hence the reaction medium contains excess of $\mathrm{Cl}^{-}$ions at higher $r$-values at constant DNA concentration. This effect is expected to give rise to the sharp increase in the rate constants in going from $r=1.5$ to 0.5 by varying Au(III) concentration (curve 1 in figure 2). Tu check the validity of this idea we added the extra $\mathrm{Cl}^{-}$ions in the reaction media of lower $r$-values to maintain a constant free $\mathrm{Cl}^{-}$ion concentration. Under this condition (case 3 ) the dependence of reaction rate constant on $r$-value is not sa sharp (curve 3 in figure 2). A ccmparison of curves 2 and 3 in figure 2 shows that after balancing free $\mathrm{Cl}^{-}$ions the dependence of reaction rate constants on $r$-value is of a similar nature in both the cases of varying DNAand $\mathrm{Au}$ (III)-concentrations as the curves run almost parallel. Apart from this effect of free $\mathrm{Cl}^{-}$ions, there is a slight decrease in reaction rate constants with the increase in $r$-value. This may be due to the presence of multiple reacting sites in DNA.

The denaturation rate constants were also calculated for all the experiments. Figure 3 shows the plots of denaturation rate constants against $r$-value for the experiments of varying $r$-values (cases 1,2 and 3 ). The denaturation rate constants increase with the increase in $r$-values when DNA-concentrations as well as DNAand free $\mathrm{Cl}^{-}$ions-concentrations are kept constant (curves 1 and 3 in figure 3 ). In the case of fixed Au(III)-concentration (case 2) the denaturation rate constants decrease with increase in $r$-values (curve 2 in figure 3 ) because in this case an increase in r-value means a decrease in DNA-concentration. Thus the denaturation rate constants increase with the increase in both the DNA and Au(III) concentrations. This is quite obvious because of the fact that in the calculation 


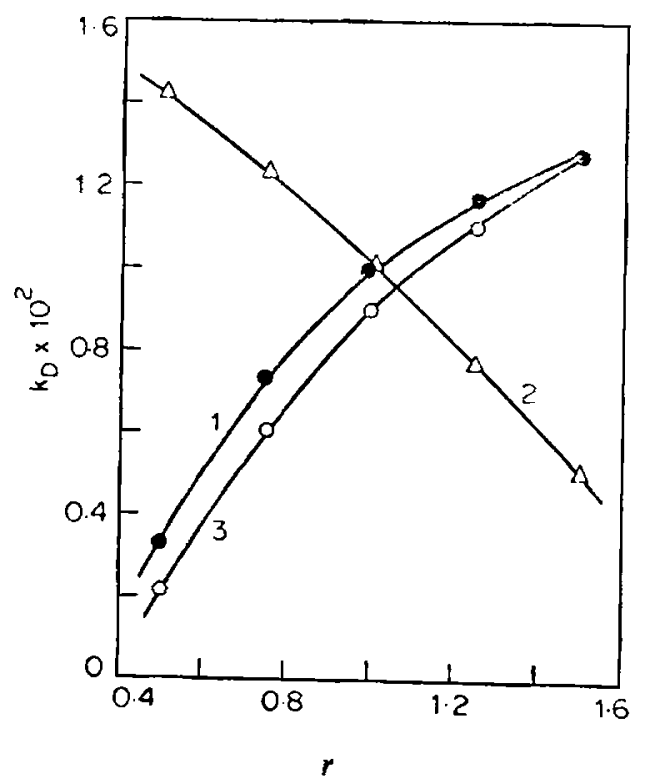

Figure 3. Plot of denaturation rato constant $\left(k_{D}\right)$ vs r-value Curve 1 , with fixed DNA-Conc $\left(=1.642 \times 10^{-4} \mathrm{M}(\mathrm{P})\right)$, Curve 2, with fixed Au(III)-Conc $\left(=1.642 \times 10^{-1} \mathrm{M}\right)$ and Curve 3 , with fixed DNA- and free $\mathrm{Cl}^{-1}$ ion concentrations; Condition : same as in figure 2 .

of the denaturation rate constants the concentration factors are not taken into account as was done in the case of reaction rate constants. Consequently the denaturation rate constants increase with increase in the DNA- and Au(III)concentrations at fixed r-values (case 4).

\section{Effect of temperature}

Two sets of experiments were carried out at six different temperatures with $r$ values 0.5 and $1 \cdot 0$. The reference solution as well as the components of the sample solution was pre-heated to the desired temperature before mixing of the reactants, the sample and the reference solutions were taken in two matched quartz cells and put in the spectrophotometer chamber which was also thermostated.

The data were treated by both the methods of reaction and denaturation kinetics. Thus two sets of reaction rate constants were obtained for $r=0.5$ and 1.0. Correspondingly, two sets of denaturation rate constants were also obtained. Rate constants were used for the calculation of activation energies by plotting the logarithm of the rate constants against the inverse of absolute temperature. Figure 4 shows the Arrhenius plots for all the four sets of rate constants. The activation energies obtained from the slapes of the plots are 16.07 and 14.59 $\mathrm{kcal} / \mathrm{mol}$ for reaction rate constants at $r=0.5$ and 1.0 respectively and the respective values for denaturation rate constants are 16.02 and $15.21 \mathrm{kcal} / \mathrm{mol}$. The activation energies are not much dependent on the $r$-values though those for 


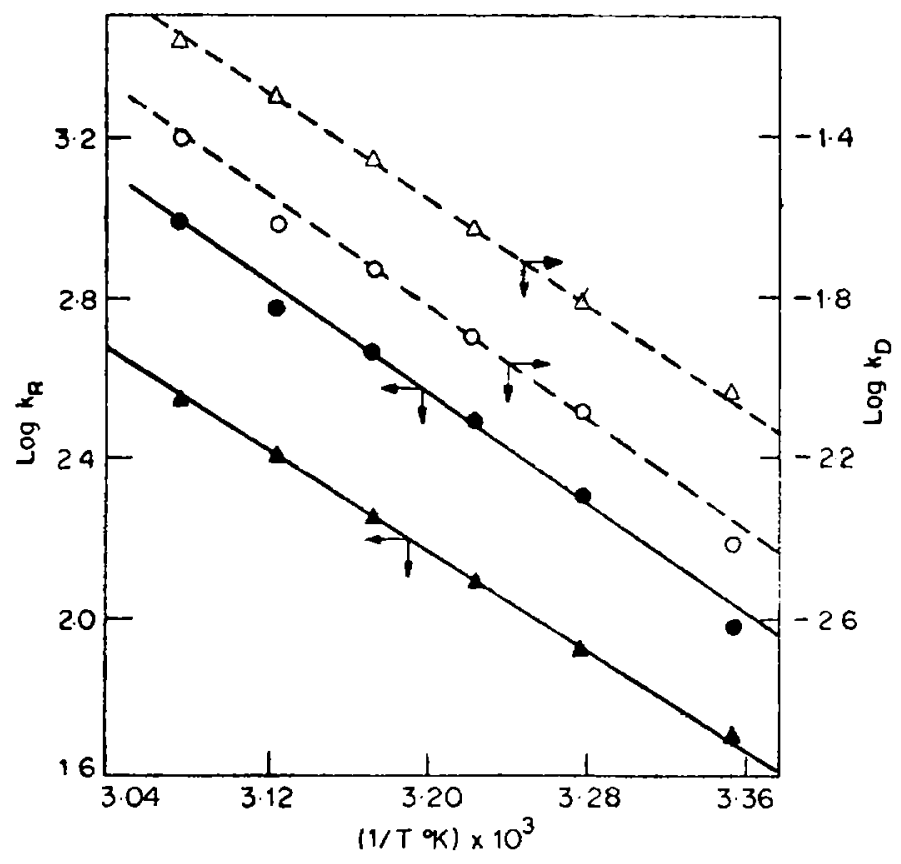

Figure 4. Plot of logarithm of rato constants vs $1 / T^{\circ} \mathrm{K}$ for $r$-values $0.5(O)$ and $1.0(\Delta)$. The solid lines are for reaction rate constants and broken lines are for denaturation rate constants (The relovant scales are shown by arrows); Condition : DNA-Conc $=1.642 \times 10^{-4} \mathrm{M}(\mathrm{P}), \mathrm{pH}=5.0$; Buffer: same as in figure 1 .

$r=0.5$ are a little higher than those for $r=1 \cdot 0$. The activation energies derived from denaturation rate constants are almost equal to those derived from reaction rate constants.

\section{Effect of lonic strength}

The ionic strength of the reaction medium was varied by adding concentrated solution of sodium perchlorate from 0.0 to $0.4 \mathrm{M}$ in addition to the buffer solution already present. Due account of the sodium perchlorate and sodium acetate was taken while calculating the ionic strengths. The concentration of acetic acid added to adjust the $\mathrm{pH}$ was not considered as most of it remained undissociated in the medium and contributed very little ions to the solution. The ionic strengths of the sample and the reference solutions were made equal for each experiment. The effect of ionic strength was studied at two different pH (viz., $5 \cdot 0$ and 4.0 ) with the r-values 0.5 and 1.0 at room temperature and constant DNA concentration. The experimental data were treated by the methods of reaction and denaturation kinetics. The rate constants were found to decrease with the increase in ionic strength. Logarithm of the rate constants were plotted against the square root of ionic strength $\left(I^{1 / 2}\right)$ for all the sets with different $r$ values and $\mathrm{pH}$ and the slopes were calculated. Figure 5 presents the plot of logarithm of the rate constants vs $I^{1 / 2}$ for the experiments at $\mathrm{pH}=5 \cdot 0$. The plots 


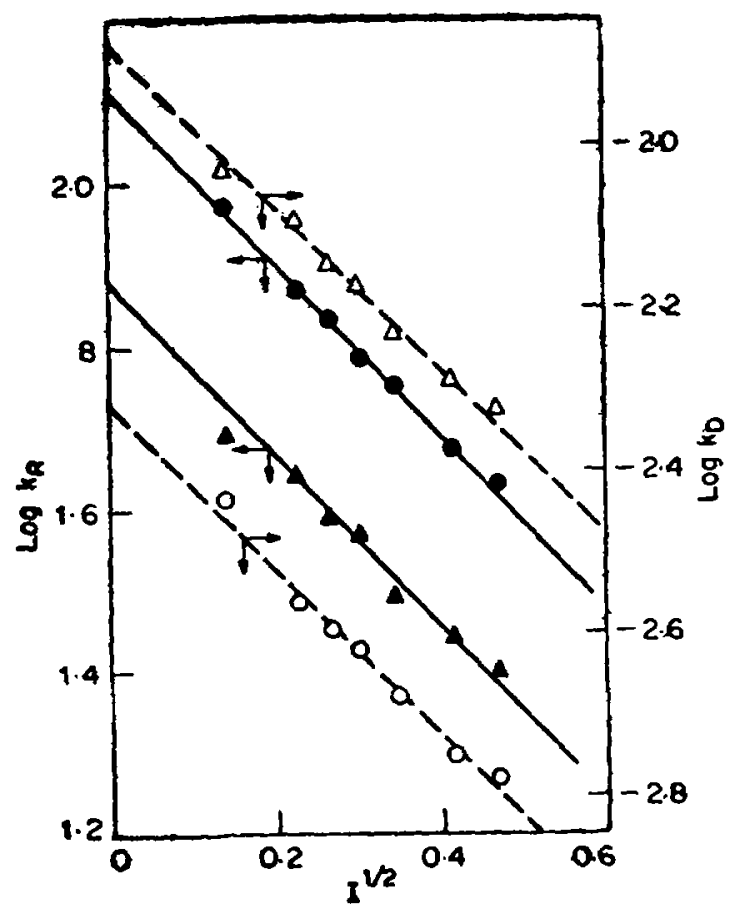

Figure 5. Plot of logarithm of rate constant vs $I^{1 / 2}$ for $r=0.5(0)$ and $1.0(\Delta)$. The solid lines and broken lines aro respectively for reaction and denaturation rate constants. Condition : DNA-Conc. $=1.642 \times 10^{-4} \mathrm{M}(\mathrm{P})$; room temperature pH $5 \cdot 0$.

are straight lines upto the value of $I=0.22 \mathrm{M}$. All the lines have almost equal slopes lying between -0.9 to -1.1 irrespective of the r-values, $\mathrm{pH}$ and the type of rate constants.

As both the species of Au(III) and DNA are expected to be charged in solution Bjerrum-Bronsted equation has bien used to examine the nature of the charges on the reacting species. The equation can be written as

$$
\log \frac{k}{k_{0}}=A Z_{A} \cdot Z_{B} \cdot I^{k},
$$

where $k_{0}$ is the rate constant at zero ionic strength, $k$ is the rate constant at a given ionic strength $I, Z_{A}$ and $Z_{B}$ are the charges on the reacting species and $A$ is a constant depending on the dielectric constant and temperature of the reaction medium. The value of $A$ for dilute aqueous solutions at $25^{\circ} \mathrm{C}$ can be taken as $1 \cdot 02$. Hence the value of the product of charges $\left(Z_{A} \cdot Z_{B}\right)$ on the reacting species is approximately -1 . This indicates that the reacting species taking part in the rate determining step are the ions of unit opposite charge; in other words, the reaction takes place between a positive and negative ion. 


\section{Effect of $\mathbf{p H}$}

The effect of $\mathrm{pH}$ was studied in the range from $3 \cdot 8$ to $5 \cdot 0$ for two values of $r$ (viz., 0.5 and 1.0) at raom temperature and constant DNA concentration. The desired $\mathrm{pH}$ values were adjusted by adding acetic acid to the sodium acetate $(0.01 \mathrm{M})$ solution containing $\mathbf{0} .01 \mathrm{M}$ sodium perchlorate. The reference solutions were of the same $\mathrm{pH}$ as the sample solutions. Bath the reaction and denaturation rate constants were found to decrease with increase in $\mathrm{pH}$ of the reaction medium. The logarithm of rate constants were plotted against the $\mathrm{pH}$ values which were straight lines. Figure 6 shows the plots for reaction rate constants for both the $r$-values. It can be seen that the slopes of the lines are dependant on the $r$-values, the values being -0.6613 for $r=0.5$ and -0.4147 for $r=1 \cdot 0$. The slopes for the denaturation rate constants are almost equal to those for the corresponding reaction rate constants. The values are -0.6667 and -0.4262 for $r=0.5$ and 1.0 respectively.

\section{Proposed mechanism and discrassion}

Let us recapitulate the characteristics of the reaction as reflected in different type of investigations.

(i) The reaction is of the first order with respect to bath the $\mathrm{Au}$ (III) and the nucleotide unit of the DNA molecule. This obviously indicates that one species of $\mathrm{Au}$ (III) reacts with one nucleotide unit in the rate limiting step.

(ii) The stoichiometry of DNA nucleotide unit to $\mathrm{Au}(\mathrm{III})$ in the overall reaction is $2: 1$. Hence finally two nucleotide units of DNA are bound to one $\mathrm{Au}(\mathrm{III})$. This indicates that there involves a fast reacting step either before or after the

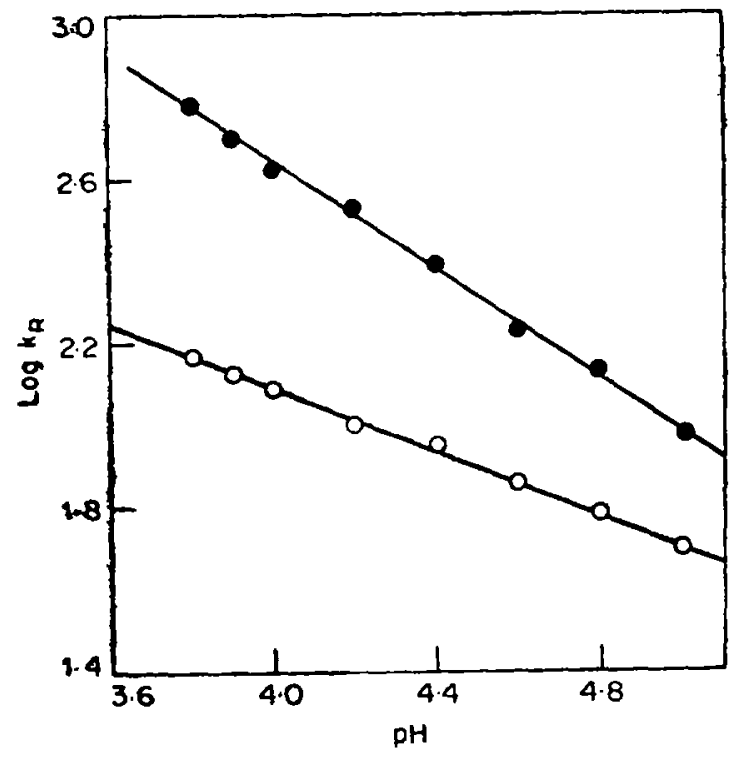

Figure 6. Plot of logarithm of reaction rate constant vs pH for $r=0.5(0)$ and $1.0(\Delta)$; Condition : DNA-Conc $=1.642 \times 10^{-4} M(P)$. Room temperature : Buffer : eamo as in Gquro 1. 
rate-limiting step. The fast step is thought to follow the rate limiting step because a cooperative and highly localised activity of a bound Au(III) would result in a very rapid binding to a second site most probably in a nucleotide unit on the complementary strand.

(iii) The dependence of reaction rate constants on the $r$-values of the reaction mixtures indicates that there exists a number of different reaction sites with slight differences in the rate constants. The observed rate constants may be the superposition of all the reaction rates. This variety of reaction rates may arise not only due to the presence of four types of bases but alsa due to the existence of different binding sites on the nucleotide units. Moreover the difference in reaction rates may also be expected due to the position of a reacting site, in question, with respect to another site which has already reacted with an Au(III); in other words, an Au(III)-bound site may affect the reaction rates of the other site present in its immediate vicinity.

(iv) The reaction is very much sensitive to the presence of chloride ions as pointed out earlier. This is partly responsible for the apparent strong dependence of the reaction rate constant on the $r$-values in the cxperiments with varying $\mathrm{Au}(\mathrm{III})$-concentrations at fixed DNA concentration. About $0.2 \mathrm{M}$ sodium chloride can almost inhibit the reaction but the addition of more than $2 \mathrm{M}$ sodium chloride cannot reverse the reaction after the equilibrium is reached. This indicates that the action of $\mathrm{Cl}^{-}$ion is kinetic rather than thermodynamic.

(v) From the kinetic study it is observed that two moles of nucleatide react with one mole of $\mathrm{Au}(\mathrm{III})$. In the existing literature, complexes with higher $\mathrm{Au}$ (III)-content has been reported. The higher complexes are not ruled out because the change in the parameter $A 250 / A 280$ is very less beyond $r=0.5$ (figure 1) and the formation of higher complexes, though occurs, cannot be detected with this method.

(vi) The Arrhenius plots give the activation energy of $14-16 \mathrm{~K} \cdot \mathrm{cal} / \mathrm{mol}$. This energy is considerably higher for breaking a hydrogen bond of energy 4-7 K. cals/mol.

(vii) From the effect of ionic strength it is clear that the reaction occurs between a positive and a negative ion. As one nucleotide is involved in the rate limiting step the negative charge on the phosphate group obviously comes into the picture. Hence the charge on the $A u(I I I)$ should be positive. In the reaction medium $\mathrm{Au}$ (III) exists mainly as $\left(\mathrm{AuCl}_{2}(\mathrm{OH})_{2}\right)^{-}$(Gibson 1969). This species is negatively charged but can give rise to a positively charged species after dissociation as follows

$$
\left(\mathrm{AuCl}_{2}(\mathrm{OH})_{2}\right)^{-} \leftrightharpoons\left(\mathrm{AuCl}_{2}\right)^{+}+2 \mathrm{OH}^{-}
$$

This dissociation will be favoured at low $\mathrm{pH}$ values as at $\mathrm{pH} 5.0$ the concentration of $\mathrm{OH}^{-}$ions is $\sim 10^{-} \mathrm{M}$. The species, $\left(\mathrm{AuCl}_{\mathbf{2}}(\mathrm{OH})_{2}\right)^{-}$, though present in higher concentration is unfavourable for the reaction because of its steric hindrance and the electrostatic repulsion between two similarly charged species.

(viii) The $\mathrm{pH}$ of the reaction medium strongly influences the rate of the reaction. The rate constants decrease with the increase in $\mathrm{pH}$ and the reaction is almost inhibited at $\mathrm{pH}=8.0$ and becomes too fast to be followed precisely below the $\mathrm{pH}=3 \cdot 8$. Again the plot of the logarithm of rate constants against $\mathrm{pH}$ is a straight line which agrees with the abave dissociation scheme. 


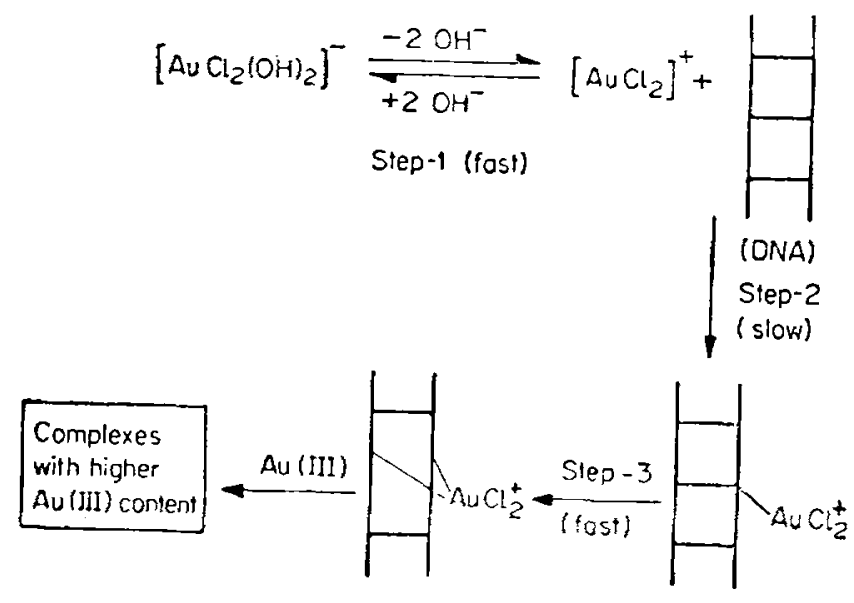

Figure 7. A schematic representation of the proposed mochanism for the reaction of Au(II) with native CT-DNA.

In keeping with all the behaviours of the reaction a mechanism has been proposed and shown schematically in figure 7. Step 1 involves the dissociation of $\mathrm{AuCl}_{2}$ $\left.(\mathrm{OH})_{2}\right)^{-}$to produce $\left(\mathrm{AuCl}_{2}\right)^{+}$which is quite fast compared to step 2 so that the equilibrium concentration of $\left(\mathrm{AuCl}_{2}\right)+$ is always maintained in the reaction medium. Had it been the rate limiting step the reaction could be of the first order with respect to $\mathrm{Au}(\mathrm{III})$ and independent of DNA concentration but that was not observed. The species $\left(\mathrm{AuCl}_{2}\right)^{+}$may exist in weakly hydrated form satisfying higher coordination number. In step 2 the species, $\left(\mathrm{AuCl}_{2}\right)^{+}$, reacts with one nucleotide unit of the DNA molecule. This step is the slowest one and determines the rate of the reaction. An important factor that makes this step very slow, is the presence of the species $\left(\mathrm{AuCl}_{2}\right)^{+}$in very low concentration because of the pre-equilibrium. This is the basic characteristic of the reaction and makes the overall process very slow compared to the other heavy metal ions like $\mathrm{Hg}$ (II). Step 3 is the rapid binding of the bound $\left(\mathrm{AuCl}_{2}\right)^{+}$to another nucleotide most probably on the complementary strand of the double helix. This step is much faster compared to step 2 because of the highly localised effects of the reacting partners. As soon as Au(III) binds to a nucleotide unit it becomes so nearer to the second nucleotide that an immiediate reaction occurs. As the bound Au(III) and the nucleotide are fixed on the strands of the DNA molecule no thermal collison is needed ta bring them together for reaction; this situation is equivalent to a very high local concentration of the reacting partners. In the subsequent steps the higher products are formed and does not come into picture as it proceeds with little change in the ratio $A 250 / A 280$. This scheme is the general representation of a group of processes in which the ligand site varies frem one to the other giving rise to a slight difference in the reaction rates. In addition to the steps described above there may be a number of other steps involved in the process like the 'breathing reaction', rearrangement, nucleation, etc., as reported in earlier literatures (Liebe and Stuchr 1972b; Williams 1968; Williams and Crothers 1975) for other metal ion DNA systems, but these steps are expected to be faster compared to the rate limiting step 2 in this system. 
The site of attachment of Au(III) cannot be accurately predicted; it may be either an the phosphate or at any site in the base moiety. Binding to phosphate, if occurs, would be chemical in nature rather than electrostatic since an electrostatic interaction would be very fast. Of course, electrostatic interacions do occur just after addition of Au(III), but the effect is very small because of very little increase in the ionic strength. The bindiug site in the base residue may be the nitrogen atoms (or oxygen atoms) of potential affinity. In the rate limiting step binding to a hydrogen bonded site is not ruled out as the activation energy is more likely to break hydrogen bond in the transition state. In fact precise prediction of binding sites cannot be made from kinetic study and we would not spect:late more about it. Our laboratory is engaged in the elucidation of the binding sites by other techniques.

With the help of this mechanism all the observed effects can be explained satisfactorily. The observed orders and stoichiometry are well accommodated in this mechanism and need no turther discussion. The presence of $\mathrm{Cl}^{-}$ions alsc decrease the rate of reaction of Pt(II) with DNA to a very large extent in which (cis Pt(II)+ and (cis Pt(II)) $)^{++}$are the reacting species (Horacek and Drobnik 1971); the function of $\mathrm{Cl}^{-}$ion being the masking of the reacting species forming stronger complexes. In the case of $\mathrm{Au}(\mathrm{III})-\mathrm{DNA}$ system the concentration of $\left(\mathrm{AuCl}_{2}\right)^{+}$ is similarly decreased with the increase in the $\mathrm{Cl}^{-}$ion concentration forming $\mathrm{AuCl}_{3}$ and $\mathrm{AuCl}_{4}$ - species.

The ionic strength of the reaction medium has diverse effects on the reaction rates of metal ions with DNA. In the reaction of $\mathrm{Hg}$ (II) (Williams 1968) the rate constants decrease with the increase in sodium perchlorate concentration and the logarithm of rate constants are the linear function of $\mathrm{pNa}^{+}$. In the reaction of $\mathrm{Cu}$ (II) with DNA (Liebe and Stuchr 1972b) the rate constants increase with the increase in the ionic strength. But for the reaction with Au(III), the rate constant ionic strength relationship is in very good quantitative and qualitative agreement with the proposed mechanism, involving the reactiun between two ions of unit opposite charge, as required ior Bjerrum-Bronsted equation (Gibson 1969). The deviation at high ionic strength is quite natural because of the approximation inherent in the equation. It should be pointed out here that even if the binding site may be on the base moiety the charge on the phosphate group would produce a full electrostatic contribution.

The $\mathrm{pH}$ of the reaction medium strongly influences the rate of this reaction and the plot of logarithm of rate constant against $\mathrm{pH}$ gives a straight line. The pH dependence of the rate constants for the Au(III)-DNA system is similar to that for $\mathrm{Hg}(\mathrm{II})$-DNA system (Williams 1968) in which the rate constants increase with the decrease in $\mathrm{pH}$ in the range 3.8 to 5.5 but different from that for $\mathrm{Cu}$ (II)-DNA in which the rate constants (i.e., the inverse of relaxation times) remain almost constant in the $\mathrm{pH}$ range $5 \cdot 3$ to $6 \cdot 2$ and increase sharply outside this range on either side. The linearity of the plot of logarithm of rate constants for the Au(III)-DNA system can be explained with the help of the proposed mechanism as follows. In step 1 the equilibrium is influenced by the $\mathrm{pH}$ of the medium. According to the reaction scheme (figure 7) the relation of the true rate constant $\left(k_{\mathrm{TB}}\right)$ of step 2 with the observed one $\left(k_{\text {oes }}\right)$ can be derived in the following way. 
The equilibrium constant $\left(K_{\text {sa }}\right)$ for step 1 is given by

or

$$
K_{\mathrm{eQ}}=\left(\mathrm{C}_{\mathrm{OH}^{-}}^{2} \cdot \mathrm{C}_{\mathrm{AUCC}_{2}^{+}}\right) / \mathrm{C}_{\mathrm{AuCl}_{1}(\mathrm{OH})_{2}} \text {, }
$$

The rate in the slowest step 2 is given by

$$
\text { Rate }=k_{\mathrm{zu}} \cdot \mathrm{C}_{\mathrm{AuCl}}^{+} \cdot \mathrm{C}_{\mathrm{DmA}(\mathrm{z})} \text {. }
$$

Combining (7) and (8) we get

$$
\text { Rate }=\left[k_{\mathrm{TR}} \cdot K_{\mathrm{OO}} / \mathrm{C}_{\mathrm{OH}^{2}}^{2}\right] \cdot \mathrm{C}_{\mathrm{AMCl}_{\mathbf{3}}(\mathrm{OR})_{2}^{-}} \cdot \mathrm{C}_{\mathrm{DNA}(\mathrm{r})} \cdot
$$

In the treatment of the kinetic data we have assumed the rate as (because $\mathrm{C}_{\mathrm{AnC} \mathrm{g}_{\mathrm{O}}(\mathrm{OB}) \text { ) }}$ $\simeq \mathrm{C}_{\mathrm{ADCl}}$ inder the experimental condition)

$$
\text { Rate }=k_{\text {Oxs }} \cdot \mathrm{C}_{\mathrm{AuCl}_{\mathbf{2}}(\mathrm{Or})_{\mathbf{2}}} \cdot \mathrm{C}_{\mathrm{DNA}(\mathrm{P})} \text {. }
$$

A comparison of (9) and (10) gives

$$
k_{\mathrm{OxS}}=k_{\mathrm{zX}} \cdot K_{\mathrm{eq}} / \mathrm{C}_{\mathrm{OH}^{-}}^{2}
$$

Taking logarithm of both sides of (11) and proper substitution of $\mathrm{pH}$ for $\mathrm{C}_{\mathrm{or}}-$ we get

$$
\log k_{\text {ows }}=-2 \mathrm{pH}+\text { const. }
$$

From equation (12) it is clear that the logarithm of the observed rate constant is a linear function of $\mathrm{pH}$. The experimental data are in good qualitative agreement with equation (12). But quantitatively the slope deviates from -2 as required by the equation and the dependence of the slope on $r$-value is also inexplicable. A quite reasonable cause of this deviation may be due to the ignorance of the influence of $\mathrm{pH}$ on the rate of the step 2. This slope of -2 is expected only from the effect of $\mathrm{pH}$ on the pre-equilibrium (step 1). The reaction in step 2 may be favoured at high $\mathrm{pH}$ values as opposed to the equilibrium. This view is supported by the observations on the interaction of $\mathrm{Au}$ (III) with the monomers. The reactions of $\mathrm{Au}(\mathrm{III})$ with nucleotides and nucleosides are favoured at high $\mathrm{pH}$ and the rates of displacement of the monomers by $\mathrm{Cl}^{-}$ions in DMSO medium are higher at low pH (Chatterjee 1978). The release of two hydroxyl ions per $\mathrm{Au}(\mathrm{III})$ at the initial stage of the reaction as studied by $\mathrm{pH}$ titration (Pillai 1974 is in good agreement with the proposed mechanism.

\section{Conclusion}

The work presented in this paper is the first systematic study on the kinetics of the interaction of Au(III) with native calf thymus DNA. The study encompasses the effect of the important parameters like concentrations, temperature, ionic strength and $\mathrm{pH}$ and leads to a plausible mechanism which explains almost all the observations. The mechanism for the Au(III)-DNA system is more or less similar to those of $\mathrm{Hg}(\mathrm{II})$-DNA and $\mathrm{Cu}(\mathrm{II})$-DNA systems but the special feature 
of this reaction is due to the primary dissociation step 1, which makes the concentration of $\left(\mathrm{AuCl}_{2}\right)^{+}$very low as a result of which step 2 becomes rate limiting.

The calculation of two types of rate constants necessitates a comment. In all the explanations we have made use of the classical reaction rate constants and, by itself, it can satisfactorily explain all the effects. But we have presented the denaturation rate constant because these are derived from a simple variable, the fraction of denaturation at a given time. A careful observation reveals that in the study of the effect of temperature, ionic strength and $\mathrm{pH}$ the results derived from denaturation rate constants are almost equal to those derived from reaction rate constants. The method of denaturation kinetics is a new computer-based method and the most important feature of this method is that with slight modification the rate parameters can be calculated even if the initial or final value of the variable parameter is not known for reactions of any order.

\section{Acknowledgements}

Part of this work was supported by the University Grants Commission, New Delhi. The authors are grateful to Dr V Kalpagam for her constant encouragement and keen interest in the work.

\section{References}

Chatterjee D 1978 personal communication

Gibson D W 1969 Dissertation thesis, John Hopkins University, Baltimore, Maryland, USA Gibson D W, Beer M and Barnett R J 1971 Biochemistry 103669

Gocch F A and Morely F H 1899 Am. J. Soc. 8261

Horacek P and Drobnik J 1971 Biochim. Biophys. Acta 254341

Liebe D C and Stuehr J E 1972a Biopolymers 11145

Liebe D C and Stuehr J E 1972b Biopolymers 11167

Piliai C K S and Nandi U S 1973 Biopolymers 121431

Pillai C K S 1974 Ph.D. Thesis, Indian Institute of Science, Bangalore

Vydra $R$ and Celikovsky J 1958 Azech. Chem. Commun. 23539

Williams M J N 1968 Dissertation thesis, Yale University, USA

Williams M N and Crothers 1975 Biochemistry 141944

Zamenhof S 1958 Biochem. prep. 68 